\section{THE STRATEGY THE USE OF FALSE ASSUMPTION AND WORD PROBLEM SOLVING}

\begin{abstract}
The paper describes one problem solving strategy - the Use of false assumption. The objective of the paper is to show, in accordance with Phylogenesis and Ontogenesis Theory, that it is worthwhile to reiterate the process of development of the concept of a variable and thus provide to pupils one of the ways helping them to eliminate usual difficulties when solving word problems using linear equations, namely construction of the equations. The paper presents the outcomes of a study conducted on three lower secondary schools in the Czech Republic with 147 14-15-year-old pupils. Pupils from the experimental group were, unlike pupils from the control group, taught the strategy the Use of false assumption before being taught the topic Solving word problems. The tool for the study was a test of four problems that was sat by all the involved pupils three weeks after finishing the topic "Solving word problems" and whose results were evaluated statistically. The experiment confirmed the research hypothesis that the introduction of the strategy the Use of false assumption into $8^{\text {th }}$ grade mathematics lessons (14-15-year-old pupils) helps pupils construct equations more successfully when solving word problems.
\end{abstract}

\section{KEYWORDS}

False assumption, word problems, false position method, phylogenesis and ontogenesis theory, problem solving

\section{HOW TO CITE}

Eisenmann P., Přibyl J., Novotná J. (2019) 'The Strategy the Use of False Assumption and Word Problem Solving', Journal on Efficiency and Responsibility in Education and Science, vol. 12, no. 2, pp. 51-65. http://dx.doi.org/10.7160/eriesj.2019.120203

\section{Petr Eisenmann ${ }^{1}$ \\ Jiři Přibyl ${ }^{1}$ \\ Jarmila Novotná \\ ${ }^{1}$ Department of mathematics, Faculty \\ of Science, Jan Evangelista Purkyně \\ University in Ústí nad Labem, Czech \\ Republic}

${ }^{2}$ Faculty of Education, Charles

University, Czech Republic

jarmila.novotna@pedf.cuni.cz

\section{Article history}

Received

November 24, 2018

Received in revised form

March 5, 2019

Accepted

March 5, 2019

Available on-line

July 1, 2019

\title{
Highlights
}

- The study describes one of the possible ways of facilitating solving of word problems to pupils.

- The experiment confirmed that introducing the Use of false assumption into 8th grade mathematics lessons can help pupils construct equations more successfully.

\section{INTRODUCTION}

Our paper focuses on the use of a once much used but nowadays overlooked solving strategy - the Use of false assumption (UFA). This strategy is rooted in ancient history (Přibyl, Eisenmann and Gunčaga, 2018). Our goal is to introduce this strategy as a suitable propaedeutic to solving word problems using linear equations. The goal of the here reported experiment conducted on three lower secondary schools in the Czech Republic was to confirm this conjecture. Pupils' ability to solve word problems efficiently is nowadays accented in national curricular documents (Jeřábek et al., 2013; National Council of Teachers of Mathematics, 2000).

\section{Introduction to the problem}

Without any doubt, mathematics education on primary and secondary school levels prepares pupils not only for solving school problems but also shows them possible ways of solving real-life situations. In everyday life, we use natural language, which is diametrically different from the artificial language of mathematics. The language of mathematics allows us to describe a problem situation unequivocally and offers us the tools for its solution. That is why it is reasonable to teach pupils to switch between the two languages at all ages. As stated in (Novotná, 2000a: 5):

'Most life situations are described in words. Word problems constitute one of the few school mathematics domains which require mathematization of situations described in words and the transformation of a mathematical solution back to the context of the problem.'

(Lewis and Mayer, 1987; Verschaffel, De Corte and Pauwels, 1992) and others show that solving a word problem is difficult 
regardless of the solver's age. We believe this is so because word problems can be regarded as linguistic descriptions of problem situations where questions are posed and the answer is obtained by application of mathematical operations to numerical or logical data available in the problem wording. In contrast to (Lewis and Mayer, 1987) we do not work with the inner structure of a word problem; for the needs of this study, we look at it from the outside. That is why we can classify verbally set problems into two categories: Word problems and Verbally stated numerical problems (De Corte, Greer and Verschaffel, 2000), which we do not consider to be word problems. An example of a word problem is problem number 3 and an example of a verbally stated numerical problem is problem number 1 (see section Written test).

However, in both cases, we ask for the translation of natural language into mathematical language, which is much easier in the latter case.

\section{The brief description of the UFA strategy}

The core of this strategy is based on experimenting with one primary aim - finding the solution.

The whole process of the use of the UFA strategy can be described as follows:

1. We choose a number which we think could be a possible

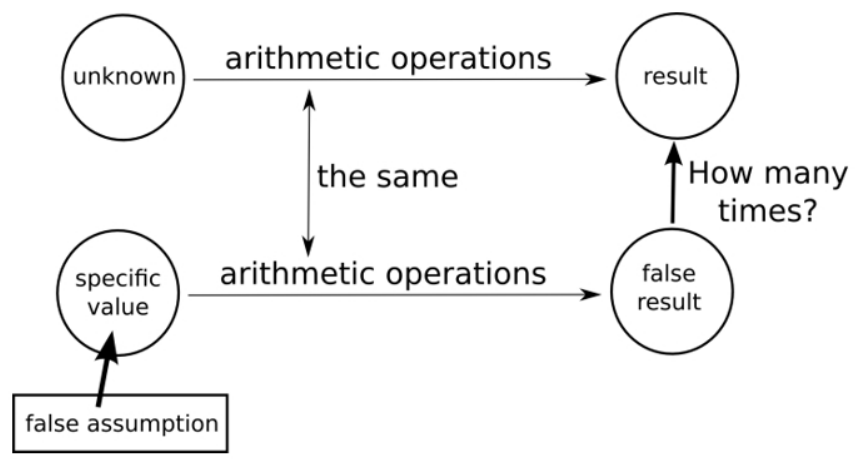

Figure 1: Schema of the process of the use of false assumption (source: authors)

Let us remark here that the UFA strategy is not universal and can only be used with a specific type of problems. It can be used successfully in solving those problems where the value of the number in the problem wording is directly proportional to the result. This means that successful use of the strategy requires from the pupil the knowledge of direct proportion and mastery of arithmetic operations with fractions. If the sought number is $x$ and the known result $y$, then the relation between the two numbers is $y=k x$.

To make the process of solving a problem using the UFA strategy crystal clear, let us demonstrate this strategy on the solution of a very simple verbally stated numerical problem.

Task A Problem: Find the number whose result if you add its triple is 200 .

Solution: Let us suppose that the desired number is for example 10 (the false assumption). Let us now carry out the operations from the problem:

$$
10+3 \times 10
$$

The result is number 40 . This number is five times smaller than 200. This means the desired number must be five times greater than our original assumption. Therefore:

$$
10 \times 5=50
$$

Answer: The number is 50 .

Let us now show why this procedure can be used in the solution of this problem. Let us present the schema of the whole solving process. Let us label the instruction 'add its triple to the number' as function $f$. This function has the character of a direct proportion. Our goal is to find such an argument whose function value equals 200 . We know that $f(10)=40$. As function $f$ is linear and 40 is five times less than 200, then also 10 must be five times less than the unknown desired number.

Let us state here that the basic idea of the UFA strategy is relatively old. Its roots go as far as the Rhind mathematical papyrus (problems no. 24-26) (Bunt, Jones and Bedient, 1978: 30-32; Chace, Bull and Manning 1929: 141-142) and even cuneiform tablets of Babylonian mathematicians (Høyrup, 2002). For more details about history, we recommend to the reader to study the third chapter of the book (Chabert, 1999).

The same idea can be come across in many later works, for example in works of G. Cardano (Smith, 1929: 201), B. Pitiscus (Smith, 1929: 437) or Fibonacci (Boman, 2009), who referred to the strategy as False position or Rule of False (Regula Falsi). Nowadays we attach very narrow meanings to the concepts of False Position Method or Regula Falsi Method. These concern numerical solutions of equations using straight lines. However, if we inspect this strategy more attentively, we can see it has two variants. The first one is Simple False Position and the other Double False Position (Chabert, 1999: 84). While the first one corresponds to our conception, the other one corresponds to the well-known concept of numerical mathematics.

\section{The UFA strategy in school mathematics}

The UFA strategy can nowadays be come across in school mathematics only in two directions. The first accentuates the motivational aspect of the historical background of the studied issue. This can be exemplified by the work (Ofir and Arcavi, 1992), where historical resources are used to motivate pupils to think about mathematics and its potential for today. However, based on an experience Ofir and Arcavi recommend the use of the presented 'Egyptian method' only with above average pupils. The other direction focuses on the use of this method in the mathematics classroom as a tool that puts emphasis on a phylogenetic approach to the teaching of different mathematical concepts. Winicki (2000) points at the fact, that if teachers want to introduce historical elements into their lessons, they must be trained to it.

\section{Importance of the problem}

Equations are usually introduced in Czech schools in the 8th grade (14-year-old pupils). At first, pupils are introduced to linear equations, then to transformations of equations and in the end to their solution. This often goes hand in hand with the model of scales, nowadays also illustrated by computer animations (Bruder and Weiskirch, 2013). Then pupils start solving word problems using equations.

A major difficulty when solving this type of problems is to set up the appropriate equation. That is natural. Even in the history of mathematics, the introduction and use of an unknown and 
thus of equation solving procedures were a slow and gradual process. For example, problems number 24-27 from the Rhind mathematical papyrus are solved using arithmetical operations with numbers. Problem number 26 gives a more detailed description of how to solve similar problems and the solver learns the solving procedure on the given example. (Chace, Bull and Manning, 1929)

The same approach can be observed in Diophantus' Arithmetica in about 250. Diophantus was able to solve relatively difficult problems. The reputed Indian mathematicians Brahmagutpa (6th century) or Bhaskara (12th century) were also able to solve very complex equations but without using the symbolic language of equations. And the same was done by al-Kwarizmi, whose work influenced European mathematics for a very long time. Works of L. Pisano, N. Chuquet or Ch. Rudolff are affected by this approach but these mathematicians were aware of the need to simplify the notation and each of them contributed to the symbolical notation of equations in their own way. The whole process culminates in the work of René Descartes, who is one of the first mathematicians introducing the concept of an unknown and symbolical recording deliberately (see e.g. Descartes, 1954). This step in development changed the approach to using equations dramatically. Equations became widespread as an appropriate instrument for problem solving.

We have proceeded from the generally accepted assumption that ontogenetic development is not independent of phylogenetic development (Brown and Heywood, 2010; Dubinsky et al., 2005). A number of authors demonstrate the relationship between the difficulties with which students are confronted during the learning process and the "breakneck" historical development within the given area of mathematics (e.g. Katz et al., 2000).

Results of Czech pupils in PISA testing when solving real-life problems are worse than the average value of other countries included in this research (Blažek and Př́ihodová, 2016; Palečková, Tomášek and Blažek, 2014).

\section{Theoretical background}

The starting point for our research was the Phylogenesis and Ontogenesis Theory (Furinghetti and Radford, 2002). On the grounds of this theory, we focused on the difficulties connected to the issue of solving word problems. We agree with (Stacey and MacGregor, 2000: 149) '...that a major reason for the difficulty is not understanding the basic logic of solving a problem by algebra.' As noted above, solving word problems is burdened with a wide range of difficulties. In the Czech school environment, we perceive the process of the mathematization of the problem as one of the biggest challenges. This process is characterized by Jupri and Drijvers (2016) as the fifth category of obstacles we can come across in word problem solving:

'Finally, the category of mathematization (MATH) concerns the difficulty to translate back and forth between the world of the problem situation and the world of mathematics, and in the process of moving within the symbolic world.' (Jupri and Drijvers, 2016: 2483)
Moreover, the whole process of word problem solving is burdened with a wide range of misconceptions (Bush and Karp, 2013).

Within the frame of Phylogenesis and Ontogenesis Theory, we focused on one of the possible ways of overcoming the abovedescribed difficulty. The reason for proposing this approach was based on a research study in historical resources. This research dealt with strategies the Use of false assumption and the Use of double false assumption as described in detail in (Přibyl, Eisenmann and Gunčaga, 2018).

The oldest of our resources was The Rhind mathematical papyrus. We had the original source available (Chace, Bull and Manning, 1929) but we studied it in the transcription of Bunt, Jones and Bedient (1978). Let us now have a look at the assignment of the often quoted problem no. 24: 'A quantity and its seventh added together give 19. What is the quantity?' (Bunt, Jones and Bedient, 1978: 30)

The given formulation clearly suggests this is a verbally stated numerical problem. The papyrus comes from the Second Intermediate Period of Egypt, which is a long time before the algebraization of mathematics. However, the papyrus itself is not a collection of problems but something like a textbook giving also the instruction on how the problems can be solved. The following is the short transcription of the solution as presented in (Bunt, Jones and Bedient, 1978: 30-32) of the solution from the Rhind papyrus (Chace, Bull and Manning, 1929: 141-142).

Let us suppose that the sought quantity is 7 . If we follow the assignment we add one seventh to the sought quantity, which is 1 . Then the result is number 8 , but it should be 19 . How many times do I have to enlarge the original guess to get

19? Number 7 must be multiplied by the fraction $\frac{19}{8}$ and the sought number is $\frac{7 \times 19}{8}=\frac{165}{8}$.

If we compare this record to our definition of the UFA strategy, we come to the conclusion that this solution corresponds to the definition. The study of further resources (see the short abovementioned historical excursion) lead us to the conclusion that the UFA strategy was around until the beginnings of the algebraization of mathematics as such. Once equations were introduced into the process of solving problems, the strategy ceased to be one of the tools of mathematicians but it gained a new role. The new role is to be looked for in textbooks of mathematics. Formerly known by the Latin name Regula Falsi, it got a new name (English translation) - the False Position Method.

The person who was greatly responsible for the inclusion of the UFA strategy into teaching materials was the important personality from the history of mathematics, Benjamin Banneker (Lumpkin, 1996). (Cajori, 1890) shows that the UFA strategy was present in mathematics textbooks until the end of the 19 th century.

Another important framework for our research is the Theory of didactical situations (TDS) in mathematics (Artigue, 
Haspekian and Corblin-Lenfant., 2014; Brousseau, 1997). This theory, among others, tells us that for each problem there is a set of prerequisite knowledge which is essential for its solution.

The UFA strategy is an example of activities that can facilitate pupils' transition from arithmetic to algebra, which has been a concern for a number of researchers (Bednarz and Dufour-Janvier, 1994; Goodson-Epsy, 1998; Linchevski and Herscovics, 1996; Novotná, 2000b). Filloy and Rojano (1989: 19) state that 'Recent researches have pointed to certain conceptual and/or symbolic changes which mark a difference between arithmetical and algebraic thought in the individual.' Based on TDS we conceived the teaching of the UFA strategy in such a way to allow pupils to discover the role of a variable on their own and to build the concept of a variable on their own. This concept is the necessary condition for the transition from arithmetic to algebra.

\section{Research question and hypothesis}

The following question was posed at the beginning of our experiment:

Research question: Is the UFA strategy a convenient propaedeutic to word problems solving using linear equations?

Based on the above stated (see section Importance of the problem) we can predict the answer to the research question by formulating our research hypothesis:

Research hypothesis: The use of the UFA strategy in the teaching of eighth graders (aged 14-15) before they are taught to solve word problems using equations will help the pupils to be more successful in constructing equations if compared to pupils who have not been introduced to the UFA strategy.

\section{MATERIALS AND METHODS}

The presented research study compares the results of pupils from experimental and control groups. Results of this study are briefly described with an emphasis on historical context in (Přibyl, Eisenmann and Gunčaga, 2018). Both experimental and control groups consisted of three classes. The inclusion of the selected class into the experimental or control groups was random. The following sections describe the preparatory stage, whose goal was to prepare the teaching experiment, to choose teachers and pupils and to conduct the teaching experiment.

\section{Preparation of the experiment}

The preparatory stage of the experiment was quite long and thoroughgoing.

In total, five seminars were held in 2013 with in-service teachers in different towns in the Czech Republic. The teachers were given problems that could be solved using the UFA strategy. Each seminar was two hours long. The teachers told us how they perceived the idea and what they predicted the results of the prepared experiment would be. In total, we discussed the experiment with about 70 lower secondary school teachers.
In the seminars, we developed a set of ten problems for the teaching experiment in collaboration with the participating teachers. All the problems were tested in five different $8^{\text {th }}$ grade classes on different lower secondary schools in the Ústí region and Prague in the year 2013. The pre-test was taken by 124 pupils.

\section{The participating teachers}

Out of the 70 above mentioned teachers, 14 participated in all five seminars. Out of these 14 teachers, three were selected for the experiment. The following criteria were used for the selection:

- The teacher was planning to teach linear equations to their pupils in 2014.

- The teacher would teach mathematics in two parallel $8^{\text {th }}$ grade classes simultaneously in 2014 .

- The teacher had taught mathematics in these parallel classes in the previous year.

- These two parallel classes (experimental and control group) were comparable with respect to school performance in mathematics.

- The teacher would be able to cooperate with researchers regularly during the whole experiment.

- The length of the teacher's practice was at least 5 years. All these three teachers can be described as engaged; they invest a lot of energy into their teaching and have attended inservice teacher training courses. They were paid for their work in the experiment. They were two men and one woman. The length of their teaching practice was 8,10 and 20 years.

\section{Research sample}

The sample was formed by three pairs of eighth grade classes from three lower secondary schools in three towns in the Czech Republic. One class was randomly chosen as the experimental class, the other was the control class in each pair of classes taught by one teacher. Pupils from these classes had not been involved in the preparatory stage. In total, there were 147 pupils involved in the experiment -72 from the three experimental classes and 75 from the three control classes. Comparability, of the experimental and control classes, was verified by a comprehensive test on topics from the previous school year, which was the same for all six classes. The results were similar in each pair of classes.

None of the classes was a specialized class. None of the classes integrated physically or mentally disabled pupils or pupils with low socioeconomic status. All the pupils were of Czech nationality with the exception of three Vietnamese and five Roma pupils. All the pupils were native speakers of Czech.

\section{The course of the experiment}

The whole experiment started in October 2014 and took 8 weeks. Its course is shown in figure 2 . The teaching in the experimental class started one week before the control class. That week was used in the control class for revision of the previous topic (in two schools) or was used as a project week (in the third school). 

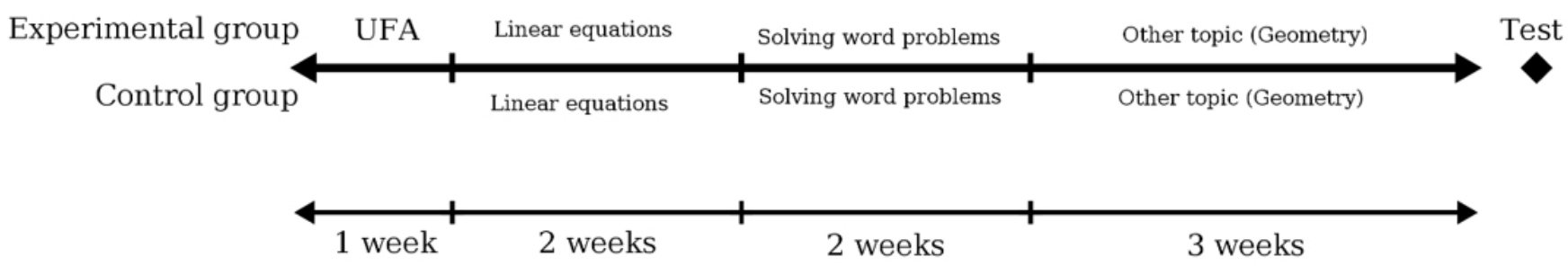

Figure 2: Timeline of the course of the experiment (source: authors)

\section{Preparatory stage in the experimental class}

At this stage, the teachers of experimental classes taught their pupils the UFA strategy. This was based on the above-mentioned set of ten problems that were presented to the pupils. The difficulty of these problems was progressive (task A forms the base of the cascade, task D is the most difficult).

When solving the first few problems for illustration, the teacher proceeded as follows: The pupils were asked to guess the result. Then they were asked to do with this guess what was required in the statement of the problem. And the teacher carried out the same with their own guess on the blackboard. Then the teacher proceeded as described in Task A. The teacher asked the pupils what should be done with the original guess to get to the number requested in the statement. This gradually led to the stage when pupils grasped the principle of solving the problem and started to be able to choose a false assumption and subsequently correct the initial guess on their own. The outcome of this stage was that at least one half of the pupils were able to solve problems such as task D. The teachers needed three lessons for this. At this stage of the experiment, the pupils were once set homework with 3 problems (before the third lesson). In the last, third lesson, a member of the research team was present in each of the three experimental classes.

Let us point out that this part of teaching can work as propaedeutic to the successful solution of problems using equations only if pupils grow aware of the fact that the choice of their guess (the false assumption) has no effect on the result of the problem, that the result will always be the same. Let us illustrate this on task A. The teachers let the pupils make the guess as they wished. Some pupils chose 5 , others 1 , others 20 . What was important was that each group demonstrated to the others how they proceeded: Choice 5 leads to:

$$
5+3 \times 5=20 \quad \rightarrow \quad 200 \div 20=10 \quad \rightarrow \quad 5 \times 10=50
$$

Choice 1 leads to:

$$
1+3 \times 1=4 \quad \rightarrow \quad 200 \div 4=50 \quad \rightarrow \quad 1 \times 50=50
$$

Choice 20 leads to:

$$
20+3 \times 20=80 \longrightarrow 200 \div 80=5 / 2 \rightarrow 20 \times 5 / 2=50
$$

The fact that "the result is always the same", in other words, that the selection of the initial guess makes no difference, is the key propaedeutic element. Growing aware of this fact prepares for the concept of a variable that we introduce into the solving process of the problem that allows us to solve it using equations. This role of numbers as building blocks for construction of the concept of the unknown is discussed by Fischer (2009: 26).

\section{The second stage in both classes}

At this stage, the course of the lessons was the same in both groups and was the following. First, the pupils were introduced to solving linear equations. This took two weeks. In the remaining two weeks the pupils went on to solve word problems with the help of linear equations. At this stage of the teaching experiment, there were situations in which some pupil from the experimental group was solving the assigned word problem using the UFA method (on average 7 times in each class). In that case, the teacher checked the result and if necessary explained the mistake in the procedure and then asked the pupils to solve the problem in the way they were being taught at that time - using a linear equation. After that, the teachers moved on to a new topic (construction problems). Let us remark here the pupils had four lessons of mathematics a week in that grade.

Three weeks after teaching equations and solving word problems (see figure 2) pupils in the experimental and control groups sat the below described written test.

\section{Written test}

The test consisting of the following four problems was sat in lessons of mathematics. The teacher was present. Each pupil got one sheet of paper with statements of all four problems. There was empty space below each problem for the solution.

Each teacher got the following instruction:

- The teacher must not give any advice or explain the problem wording.

- Use of any textbooks, tables or collections of formulas is prohibited.

- Use of any calculators, computers, laptops or tablets is prohibited.

- The pupils must write the solving procedure or record the reasoning that leads to the result, not just the result.

- The pupils must write a verbal answer or double underline the result.

- The pupils have a maximum of 40 minutes for the test.

\section{Problems:}

1. One third of an unknown whole number reduced by $20 \%$ is 32 . What is the unknown number?

2. The perimeter of a rectangle is $60 \mathrm{~m}$. Determine the lengths of its sides if you know that they are in the ratio $7: 3$.

3. Mr Hare is a successful rabbit breeder. Having bred rabbits for three years, he now has 45 rabbits. He expanded his husbandry by adding to the number of bred animals its double at the end of each year. How many rabbits did $\mathrm{Mr}$ Hare have at the end of his first year? 
4. The price of a TV set was put up by one quarter. However, nobody wanted to buy it so the price was reduced by one half of the new price. Then it cost $10,000 \mathrm{CZK}$. What was the original price of the TV set?

All these problems can be solved using linear equations. The difficulty of the test problems is on a medium level when compared to problems used in lessons when teaching word problems solved by linear equations.

The problems for the written test were selected in such a way to make them correspond to problems the pupils had usually been solving in lessons and to involve both types of verbally given problems (word problems and verbally stated numerical problems) in the same number.

After their completion, the pupils' tests were coded. Each problem in the test was labelled by the following code:

group / number of problem / correctness of solution / way of solution / specification of the way of solution

The items of the code have the following values:

- Group: $\mathrm{e}$ - pupil is from an experimental class, $\mathrm{k}$ - pupil is from a control class.

- Number of problem: 1-4.

- Correctness of solution: 1 - successfully solved problem, 0 - unsuccessfully solved problem, $\mathrm{x}$ - pupil has not solved the problem.

- Way of solution: $\mathrm{r}$ - pupil uses a linear equation, $\mathrm{u}$ - pupil uses the strategy Use of false assumption, $\mathrm{h}$ - pupil uses another way of solution (usually heuristic strategy), n nonsense, $\mathrm{x}-\mathrm{a}$ pupil has not solved the problem.

- Specification of the way of solution:

- If a pupil is unsuccessful in solving the problem (correctness of solution is 0 ) and uses a linear equation for its solution, then: $\mathrm{A}$ - if the linear equation is correctly constructed, $\mathrm{N}-$ if the linear equation is not correctly constructed.

- If a pupil uses another way of solving: POK - a pupil uses the Guess-Check-Revise strategy, SE - a pupil uses the Systematic Experimentation strategy, CZ a pupil uses the Working backwards strategy.

○ “-” (dash) in all other cases.

Examples of the coding procedure:

- Code (e/2/1/r/ - ) means: the pupil is from an experimental class and solved the second problem of the written test successfully, using a linear equation.

- Code $(\mathrm{k} / 1 / 0 / \mathrm{r} / \mathrm{A})$ means: the pupil is from a control class and solved the first problem of the written test unsuccessfully. The pupil used the formulated equation correctly.

- Code (e / $3 / 1 / \mathrm{h} /$ POK) means: the pupil is from an experimental class and solved the third problem of the written test successfully, using heuristic strategy GuessCheck-Revise.

Some remarks:

- The coding of all written tests was carried out by one researcher.

- No information was recorded about the pupil since we were interested in the results of the group, not individuals.

- If pupils used more ways of solution, it was coded according to the following key:

- If a problem were solved both using linear equations and the UFA strategy or some other way of solution, then the problem was coded as solved using a linear equation.

- If a problem were solved using the UFA strategy and some other way, then it was coded as solved using the UFA strategy.

- Having coded all problems, the results were processed by the Statistica 12 software (StatSoft, Inc., 2013).

\section{Data analysis}

To test the null hypothesis, the test of equality of two parameters of alternative distributions was used. Software Statistica 12.0 (StatSoft, Inc., 2013) was used for all statistical evaluation.

\section{A priori analysis of test problems}

In this section, the a priori analysis of the four test problems is presented. This analysis was conducted with the aim of verification of the suitability of test problems with respect to the main objective of assigning the test - to reject or fail to reject of our research hypothesis. That is why it is natural to ask about the expected possible ways of pupils' solutions of the problems.

The next two sections give a description of the results of the a priori analysis that are the same for all four problems and the results of the a priori analysis of the $3^{\text {rd }}$ problem.

The a priori analysis focused on the following aspects of the problems:

- Justification of the legitimacy of the use of the UFA strategy

- Characteristics of the problem

- Knowledge and skills needed for the successful solution of the problem

- Algorithmic school solving strategy

- Solving the problem using the UFA strategy

- Overview of other possible ways that can be used for the solution of the problem

- List of possible solvers' mistakes and risks in solving the problem

\section{Results of the a priori analysis common to all problems}

With respect to the selection of problems, it may be stated that the following results of the analysis are the same for all four problems. Justification of legitimacy of the use of the UFA strategy - each of the problems is underlain by a function expressing the dependence of the sought unknown number which has the character of direct proportion.

Characteristics of the problem - in all cases it is a two-level problem. As stated above, verbally stated problems are divided into two groups for the needs of this research study, namely: (a) verbally stated numerical problem - problems 1 and 2 and (b) word problems - problems 3 and 4.

Knowledge and skills needed for the successful solution of the problem - the following skills and knowledge are prerequisite for this kind of problems:

- mathematization of a verbally assigned text; 
- arithmetical operations on natural numbers;

- $\quad$ arithmetical operations on rational numbers.

Overview of other possible ways that can be used for the solution of the problem - due to the experimental character of the UFA strategy, the given problems may be solved using also strategies Guess-Check-Revise and Systematic Experimentation.

List of possible solvers' mistakes and risks in solving the problem - the risks of using the UFA strategy are of general nature and are the following:

- The pupil fails to understand the relations from the problem wording and is unable to construct the expression with the false assumption.

- The pupil understands the relations from the problem wording and constructs the expression with the false assumption but does not understand the relation between the number calculated from the false assumption and the value in the problem wording.

- The pupil chooses the false assumption in a way that makes the corresponding coefficient, not a whole number, which makes further calculations much more difficult or impossible.

\section{Results of a priori analysis of the $3^{\text {rd }}$ problem}

Justification of the legitimacy of the use of the UFA strategythe function expressing the dependence of the sought unknown number from the data given in the problem assignment really has the character of a direct proportion. It is the function $f(x)$ from point 4.

Characteristics of the problem - this is a two level word problem with the same rule for calculation but a different base. Knowledge and skills needed for the successful solution of the problem - mathematization of a verbally given text, understanding the whole and its part, arithmetical operations with natural numbers, the solution of simple linear equations Algorithmic school solving strategy - solution using an equation:

$x \ldots$ the number of rabbits at the end of the first year

$x+2 x=3 x \ldots$ the number of rabbits at the end of the second year

$3 x+2 \cdot(3 x)=9 x \ldots$ the number of rabbits at the end of the third year

$f(x)=9 x \ldots$ the function describing the number of rabbits

$9 x=45$

$x=5$

Mr Hare had 5 rabbits at the end of the first year.

Solving the problem using the UFA strategy - let us assume Mr Hare had one rabbit at the end of the first year. Now let us record the number of rabbits at the end of each year in table 1.

\begin{tabular}{c|c|c} 
Year & New rabbits & Has \\
\hline 1. & - & 1 \\
\hline 2. & 2 & 3 \\
\hline 3. & 6 & 9
\end{tabular}

Table 1: Solution of problem 3 using the UFA strategy (source: own calculation)
In this case, Mr Hare would have 9 rabbits at the end but he should have 45 that is five times more. This means Mr Hare had 5 rabbits at the end of the first year.

Overview of other possible ways that can be used for the solution of the problem - Guess-Check-Revise, Systematic Experimentation, Solution drawing

List of possible solvers' mistakes and risks in solving the problem -

The algorithmic way of the solution:

- The pupil does not understand the information from the problem wording and instead of adding a double of the number of rabbits they only double the number of rabbits.

- The pupil interprets the information about the increase of the number at the end of the year incorrectly and adds a double of the initial number of rabbits already in the first year.

- The pupil solves the equation incorrectly.

The use of false assumption strategy:

- The pupil does not understand the relations from the problem wording and fails to construct the expression with the false assumption.

- The pupil understands the relations from the problem wording and constructs the expression with the false assumption (the table in the model solution) but fails to understand the relation between the correctly calculated number for the false assumption and the value from the assignment. Thus they do not know how to use the calculated number.

- The pupil selects the false assumption in a way that the corresponding coefficient is not a whole number, which makes further calculations very difficult or impossible.

\section{RESULTS}

In total, 588 problems (each pupil solved 4 problems) were coded. Based on the coding we can state the following:

- All the pupils solved all the problems, that is the value " $x$ " appeared in none of the codes.

- With the exception of two problems, it was always possible to identify the way of solution of the problem by the pupil. The code " $n$ " appeared once in the experimental group (problem 3 ) and once in the control group (problem 2).

- In two problems (problems 3 and 4) (each by a different pupil), two ways of solution were used, always a solution using some other way and using a linear equation. In both cases, the equation was constructed correctly and solved successfully. According to the agreed upon key both of these occurrences were coded as " $r$ ". Let us remark here that problem 3 was solved in this way by a pupil from the experimental group, problem 4 by a pupil from the control group.

The following table 2 presents results with respect to the studied issue. The figure in front of the hyphen gives the number of pupils who used a linear equation when solving the problem, the figure behind the hyphen states how many of them were successful and solved the problem correctly using this way. 


\begin{tabular}{ccc} 
Problem & Group & Equation \\
\multirow{2}{*}{1} & Experimental & $43-31$ \\
\cline { 2 - 3 } & Control & $51-20$ \\
\hline \multirow{2}{*}{2} & Experimental & $40-28$ \\
\cline { 2 - 3 } & Control & $41-19$ \\
\hline \multirow{2}{*}{3} & Experimental & $41-24$ \\
\cline { 2 - 3 } & Control & $45-18$ \\
\hline \multirow{3}{*}{4} & Experimental & $49-40$ \\
\cline { 2 - 3 } & Control & $55-27$ \\
\hline
\end{tabular}

Table 2: Solving test problems using equations ( $N_{E}=72, N_{c}=75$ ) (source: own calculation)

The third column in table 2 shows that if pupils were solving the problem using equations, they were always more successful in the experimental groups than in the control groups. The null hypothesis about an equal probability of success in experimental and control classes was tested. The null hypothesis can be rejected with the level of significance 0.05 in all problems. The $p$-values for the problems are respectively: $0.0007,0.0144,0.0392$ and 0.0002 .

The following tables show frequencies of situations that occurred in the case the pupils tried to solve the given problem using equations. The number of pupils who constructed the right equation is given in columns two and three of tables 3-6. The pupils who managed to solve the equation and reach the correct result are in column two. The last column gives the number of pupils who tried to construct a corresponding equation but failed.

These tables clearly show that if pupils were able to construct a correct equation they were in most cases successful when solving it. What is crucially important here is that pupils in the experimental classes were more successful in constructing the equations. The null hypothesis on equal probability of success of pupils from the experimental and the control classes was tested again. The null hypothesis can be rejected with the level of significance 0.05 in all problems. The $p$-values for the problems are respectively: $0.0002,0.0127,0.0392$, and 0.0001 . For the sake of completeness, we present an overview of the overall success rate of pupils in each problem in table 7 . It is quite interesting to see that some pupils from the experimental group use the UFA strategy in their solving although the strategy was introduced in lessons seven weeks before the test and they were introduced to linear equations in-between.
Their numbers are given in the fifth column, where the figure in front of the hyphen gives the number of pupils who used this strategy, the figure behind the hyphen states how many of them were successful and solved the problem correctly using this way. To provide a complete view, in the sixth column we present the numbers of pupils who solved the problem in some other way, usually with a method identified as one of heuristic strategies the pupils had not been introduced to in their lessons (Working Backwards, Guess-Check-Revise or Systematic Experimentation).

\begin{tabular}{c|ccc|c}
\multirow{2}{*}{ Group } & \multicolumn{2}{|c|}{ Constructed the right equation } & $\begin{array}{c}\text { Did not } \\
\text { construct the } \\
\text { right equation }\end{array}$ \\
\hline Experimental & 31 & Did not resolve & 2 & 10 \\
\hline Control & 20 & 1 & 30 \\
\hline
\end{tabular}

Table 3: Problem 1 ( $N_{E}=43, N_{C}=51$ ) (source: own calculation)

\begin{tabular}{|c|c|c|c|}
\hline \multirow{2}{*}{ Group } & \multicolumn{2}{|c|}{ Constructed the right equation } & \multirow{2}{*}{$\begin{array}{l}\text { Did not } \\
\text { construct the } \\
\text { right equation }\end{array}$} \\
\hline & Resolved & Did not resolve & \\
\hline Experimental & 28 & 2 & 10 \\
\hline Control & 19 & 2 & 20 \\
\hline
\end{tabular}

Table 4: Problem 2 ( $N_{E}=40, N_{C}=41$ ) (source: own calculation)

\begin{tabular}{c|ccc|c}
\multirow{2}{*}{ Group } & \multicolumn{2}{|c|}{$\begin{array}{c}\text { Constructed the right equation } \\
\text { Resolved }\end{array}$} & $\begin{array}{c}\text { Did not } \\
\text { Did not resolve } \\
\text { right equation } \\
\text { right the }\end{array}$ \\
\hline Experimental & 24 & 1 & 16 \\
\hline Control & 18 & 1 & 26 \\
\hline
\end{tabular}

Table 5: Problem 3 ( $N_{E}=41, N_{C}=45$ ) (source: own calculation)

\begin{tabular}{c|cc|c}
\multirow{2}{*}{ Group } & \multicolumn{2}{|c|}{ Constructed the right equation } & $\begin{array}{c}\text { Did not } \\
\text { construct the } \\
\text { right equation }\end{array}$ \\
\hline Experimental & 40 & Did not resolve & 3 \\
\hline Control & 27 & 2 & 6 \\
\hline
\end{tabular}

Table 6: Problem 4 ( $N_{E}=49, N_{C}=55$ ) (source: own calculation)

\begin{tabular}{ccc|c|cc} 
Problem & Group & Total & Equation & Use of false assumption & Other way \\
\cline { 2 - 6 } 1 & Experimental & $72-50$ & $43-31$ & $12-10$ & $17-9$ \\
\cline { 2 - 6 } & Control & $75-31$ & $51-20$ & $0-0$ & $24-11$ \\
\cline { 2 - 6 } 2 & Experimental & $72-44$ & $40-28$ & $16-10$ & $16-6$ \\
\hline \multirow{2}{*}{3} & Control & $75-27$ & $41-19$ & $0-0$ & $34-8$ \\
\hline \multirow{2}{*}{4} & Experimental & $72-38$ & $41-24$ & $10-5$ & $21-9$ \\
\hline \multirow{2}{*}{4} & Control & $75-32$ & $45-18$ & $0-0$ & 14 \\
\hline & Experimental & $72-53$ & $49-40$ & $10-5$ & $13-8$ \\
\hline
\end{tabular}

Table 7: The ways of test problems solving ( $N_{E}=72, N_{c}=75$ ) (source: own calculation) 


\section{DISCUSSION}

The goal of the here presented study was to find out whether the introduction of the UFA strategy in mathematics lessons before teaching linear equations has a positive impact on pupils' ability to construct equations, which is imperative for solving word problems in the $8^{\text {th }}$ grade.

The whole process of solving a problem has several stages. Pólya (2004) identifies these stages as (a) understand the problem; (b) devise a plan; (c) carry out the plan; (d) look back. In case of arithmetic word problems, other authors (Lewis, 1989; Morin et al., 2017) specify the stages of the solution more: (a) familiarize oneself with the problem; (b) translate the written information into a mathematical equation or system of equations; (c) solve the equation(s); (d) check one's answer in the original problem; (e) state the answer clearly in written form.

Obviously, a necessary condition for a successful solution of word problems is the construction of an appropriate equation, which corresponds to what Boonen et al. (2016: 2) state:

'That is, word problem solvers have to use a problemmodel strategy in which they translate the problem statement into a qualitative mental representation of the problem situation hidden in the text. This mental representation subsequently allows them to make a solution plan and execute the required mathematical operations.'

Constructing an appropriate equation is not the only necessary condition. If a pupil is to construct an appropriate equation, they must be able to get the needed information from the given problem. However, research on the influence of a pupil's reading comprehension abilities has not been subject to this study.

\section{The impact of UFA on success when constructing equations}

For the needs of this research study, verbally formulated problems are divided into two basic categories, namely: (a) verbally stated numerical problems; (b) word problems. The problems included in the written test are divided as follows: problems 1 and 2 are from the category (a), problems 3 and 4 from the category (b).

Let us focus on the success rate in setting up appropriate equations. As mentioned in the methodology part of this research study, we conceive an appropriate equation as a correctly constructed linear equation whose solution bears the required result.

Table 3 shows that the success rate in constructing the equation in Problem 1 was $77 \%$ in the experimental group and $41 \%$ in the control group. Similarly, table 4 shows that pupils in the experimental group were successful when constructing the equation in problem 2 in $75 \%$ of cases while pupils in the control group only in $51 \%$ of cases. Problem 1 is a purely arithmetic problem that asks for no further knowledge, whereas problem 2 uses non-arithmetic concepts of a rectangle and its perimeter. With respect to the length of the verbal assignment in Czech, both problems were comparable. It is quite interesting to remark here (although this was not subject to the research study) that if an equation was constructed correctly, then failure in its solution was comparable in both groups (see tables 3 and 4).
Table 5 shows that the success rate in constructing the equation in problem 3 was $61 \%$ in the experimental and $42 \%$ in the control groups. Similarly, table 6 shows that the success rate of pupils in the experimental group in problem 4 was $88 \%$ while of pupils in the control group 53\%. Problems 3 and 4 contained a non-mathematical (in this case pseudo-real) context. With respect to the length of the verbal assignment in $\mathrm{Czech}$, both problems were comparable. Also, in this case, it holds that if an equation was constructed correctly, then failure in its solution was comparable in both groups (see tables 5 and 6).

As stated in the methodology section, the research sample and the design of the experiment were chosen in such a way to eliminate any extraneous variables as much as possible and thus to be able to focus on answering the research question fully. We can state here that the only aspect in which the groups differed was the introduction of the UFA strategy in mathematics lessons before introducing linear equations in the experimental group.

Based on the above stated results - rejection of the null hypothesis on the equal probability of success of pupils from the experimental and the control groups - we can answer the research question as follows: The use of the UFA strategy in the teaching of eighth graders (aged 14-15) before they are taught to solve word problems using equations helps pupils to be more successful in constructing equations if compared to pupils who have not been introduced to the UFA strategy.

To conclude let us point out here that this is not the only way to facilitate learning to construct appropriate equations. The research (Boonen et al., 2013; Lewis, 1989), which focuses on the analysis of problems, divides arithmetic problems into several groups. For each group, it then presents appropriate visual or mental representations that facilitate either a pupil's grasping of the problem or construction of an appropriate equation. In our research study, we put emphasis on the idea of a genetic parallel (Phylogenesis and Ontogenesis Theory) after we studied the use of the UFA strategy in the solution of problems in the past, and reiterated this process with our pupils.

\section{The UFA strategy and other ways of transition from arithmetic to algebra}

Most publications on the UFA strategy focus on its use in teacher education, especially in the context of showing historical solving procedures to teachers. For example Winicki (2000) describes a workshop for teachers in which the UFA strategy was used as a tool for getting to understand the solution of linear equations. The target group were teachers who did not teach their pupils to solve linear equations and functions; in their case, it was essential that they should understand mathematical principles because they were teaching e.g. proportion and proportionality. The participants of the workshop focused on the questions such as for what type of equations the UFA strategy was a suitable strategy, whether the result depended on the selected assumption and what advantages the participants could see in its use.

In our research, we followed a different path. The UFA strategy was taken as a tool facilitating pupils' transition from arithmetic to algebra in word problem solving. 
Let us remark here that the UFA is not the only tool supporting understanding of solution of problems on linear equations. Other heuristic strategies, studied for example in (Eisenmann et al., 2015) suitable for these ends are the strategies Guess-CheckRevise, Systematic Experimentation and Solution drawing (in our case a line segment legend (Novotná, 2000b)). Table 8 gives an overview of some advantages and disadvantages of the given strategies in the facilitation of solution of word problems based on a linear equation.

\begin{tabular}{|c|c|c|c|}
\hline & UFA & $\begin{array}{c}\text { Guess-Check-Revise, Systematic } \\
\text { Experimentation }\end{array}$ & Use of line segments \\
\hline Applicability & $\begin{array}{l}\text { Only for problems of the type direct } \\
\text { proportion } \\
\text { For problems of discrete and } \\
\text { continuous character }\end{array}$ & $\begin{array}{l}\text { For a wide range of problems of } \\
\text { discrete character } \\
\text { In case of problems of continuous } \\
\text { nature no solution may be found }\end{array}$ & $\begin{array}{l}\text { For a wide range of problems of } \\
\text { discrete character, suitable especially } \\
\text { for problems on division of the } \\
\text { whole into unequal parts }\end{array}$ \\
\hline $\begin{array}{l}\text { Speed of finding } \\
\text { a solution }\end{array}$ & $\begin{array}{l}\text { A very fast procedure: } \\
\text { Having calculated the result for the } \\
\text { false assumption, a coefficient may } \\
\text { be determined by which the original } \\
\text { false assumption is multiplied. }\end{array}$ & $\begin{array}{l}\text { It can be very protracted and } \\
\text { numerically demanding, it depends } \\
\text { on how far the first guess was from } \\
\text { the final result. }\end{array}$ & $\begin{array}{l}\text { Illustrative procedure that brings the } \\
\text { solver to the result relatively quickly } \\
\text { if the solution drawing is sketched } \\
\text { well. Note: Although there might } \\
\text { be no letters in the solution, the } \\
\text { procedure is of algebraic nature, the } \\
\text { unknown is represented by a line } \\
\text { segment. }\end{array}$ \\
\hline $\begin{array}{l}\text { Grasping the role } \\
\text { of an independent } \\
\text { variable }\end{array}$ & Yes & Yes & Yes \\
\hline $\begin{array}{l}\text { Spontaneity of } \\
\text { choice of strategy }\end{array}$ & $\begin{array}{l}\text { Requires introduction of the strategy, } \\
\text { its spontaneous use without prior } \\
\text { experience cannot be expected }\end{array}$ & Often chosen spontaneously & $\begin{array}{l}\text { Requires introduction of the line } \\
\text { segment model, spontaneous use } \\
\text { without prior experience cannot be } \\
\text { expected }\end{array}$ \\
\hline Possible problems & $\begin{array}{l}\text { Use in situations that are not the } \\
\text { type of direct proportion } \\
\text { If the assumption is not opportune, } \\
\text { the coefficient may be a non-whole } \\
\text { number }\end{array}$ & $\begin{array}{l}\text { Very long calculations resulting in } \\
\text { a loss of motivation to solve the } \\
\text { problem until the end } \\
\text { In case of successful discovery of } \\
\text { the solution, pupils may start using } \\
\text { the strategy as an algorithm and lose } \\
\text { motivation to use equations }\end{array}$ & $\begin{array}{l}\text { Wrong depiction of relations } \\
\text { In case of successful discovery of the } \\
\text { solution, pupils may start using the } \\
\text { strategy as an algorithm and lose } \\
\text { motivation to use equations }\end{array}$ \\
\hline
\end{tabular}

Table 8: Comparison of the UFA strategy with Guess-Check-Revise, Systematic Experimentation and Solution drawing (source: own research)

We are fully aware of the fact that heuristic strategies are not the only way of facilitating the transition from arithmetic to algebra. The background of the whole process is based on a generalization of arithmetic thinking up to the level of algebraic thinking and reasoning. Some heuristic strategies may be introduced already at primary school level (Jacobs et al., 2007), which then makes the transition from arithmetic to algebra easier at the secondary school level.

\section{A posteriori analysis of test problems}

Justification of the legitimacy of the use of the UFA strategy and characteristics of the problem - as shown in the a priori analysis, all problems in the test were chosen appropriately. They are two level problems, all of which have a linear dependence in the background. The problems were also divided into two groups according to their wording - verbally stated numerical problems 1 and 2, and word problems 3 and 4. Knowledge and skills needed for the successful solution of the problem - The pupils had all the knowledge and skills needed for the successful solution of the problems. The pupils had already been introduced to rational numbers. Mathematization of verbally stated problems was the topic of the lessons within the frame of the teaching experiment in progress.
Algorithmic school solving strategy-the anticipated algorithmic school solution of the given problems corresponded to the use of linear equations that the pupils had to construct. The practice of solving linear equations was the topic of the lessons within the frame of the experiment in progress. Let us remark here that if the pupils constructed the appropriate equation correctly, they were almost always successful in its solution. In each of the problems, there were one to three pupils who had failed to solve the problem despite having constructed the equation correctly. This was independent of the group they belonged to (see tables 3 to 6).

Solving the problem using the UFA strategy - although this was not subject to the here presented research, pupils from the experimental group had the chance to solve the given problem using the UFA strategy. Table 7 shows that this actually happened in each of the test problems. It is important to note that the use of the UFA strategy did not necessarily bring the successful solution to the problem. Analysis of pupils' solutions shows that pupils who used the UFA strategy for the solution of the given problem did not even try to construct the appropriate equation, in other words, the strategy became for them an equivalent to the algorithmic way of the solution. Overview of other possible ways that can be used for the 
solution of the problem - table 7 shows that pupils solved the given problems also using other ways than using linear equations or the UFA strategy. From our research (Eisenmann et al., 2017) we know there are heuristic strategies whose occurrence is spontaneous and that can be come across without having been taught. In some cases, their use is encouraged by the nature of the problem itself.

In our a priori analysis, we predicted the occurrence of experimental strategies Guess-Check-Revise and Systematic Experimentation. While the first strategy was to be met in the solutions of all four problems, the other was not used for the solution of any of the problems. A strategy used unexpectedly was Working backwards, namely in the solutions to problems 1,3 and 4 .

In the strategy Guess-Check-Revise we first check whether we have a solution and if not we make a revision which we believe will take us closer to the goal - in other words, we conduct a new experiment. And we carry on doing this until we get the solution. This strategy is universal and is used frequently in many different types of problems from various areas of mathematics.

The idea of Systematic experimentation is based on conducting experiments in an organized way in which each following experiment takes us "closer" to the desired goal. The strength of this strategy is even more apparent if we use computer technology. First, we make a key to how to conduct the experiments and then using a computer (most often spreadsheet) we conduct a whole series of experiments. The strategy is limited by the creation of the right key.

The strategy Guess-Check-Revise and Systematic experimentation in solving problems from school mathematics are discussed in detail in (Břehovský et al., 2013; Novotná, Eisenmann, and Přibyl, 2014; Novotná et al., 2014).

Working Backwards is a strategy commonly used in mathematics in situations when we know the "result" of the problem and are looking for the solving procedure (for example we know the initial state) or for the initial state (we know the solving procedure). An example of the first are problems from geometric construction, an example of the latter are problems in which we look for inverse operations to the given operations. Pupils involved in the experiment (both control and experimental groups) were not trained to be problem solvers for any considerable period of time and thus can be perceived as novices in the area. As Gick (1986) states it is exactly this group of solvers who tend to work backwards if the nature of the problem allows it.

Solvers' mistakes in solving the problem - apart from the mistakes mentioned in case of solution using the UFA strategy and algorithmic way of solution, the biggest problem is still the process of the mathematization of the problem as such, that is the construction of an appropriate equation, see tables 3 to 6. An expected phenomenon was that pupils from the control group would be less successful in the construction of equations, which actually happened. However, the number of pupils from the experimental group who failed to construct the equations correctly was far from negligible. Let us look at each of the problems in more detail.

In case of problems 1 and 2 (verbally stated numerical problem), the number of pupils in the experimental group who failed to construct the correct equations is one quarter of those who tried to construct it. The analysis of the pupils' solutions shows that in case of problem 1 this is caused by the high number of consecutive arithmetic operations that are related to the whole. In case of problem 2, the difficulty comes out of the fact that pupils labelled the two sides of the rectangle by two different variables, which made them construct an equation with two variables or a system of equations, which they were not able to solve.

In case of problems 3 and 4 (word problems), the situation is different. In case of problem 3, the number of pupils in the experimental group who failed to construct the correct equations equals $39 \%$ of those who tried to construct it. That is why we present a full a priori analysis of this problem. In case of problem 4, the situation is the opposite and the number of pupils in the experimental group who failed to construct the correct equations equals $12 \%$ of those who tried to construct it. We believe this high success rate can be ascribed to the small number of arithmetic operations. The mistakes that could be come across in the construction of equations were in most cases caused by wrong use of the basis.

\section{Pitfalls in the use of the UFA strategy}

As a posteriori analysis showed, a number of pupils used the UFA method while solving the problems in the written test. That is why we should ask whether the UFA strategy is an appropriate tool for the solution of arithmetic word problems. We are fully aware of the fact that the introduction of this strategy in mathematics lessons bears some risks.

\section{Problems of non-linear nature}

The first pitfall in the use of the UFA strategy is that a pupil must be able to tell whether the particular problem may or may not be solved using this strategy. In other words, they must be able to tell whether there is a direct proportion in the background of the problem. The following two problems illustrate inappropriate uses of the UFA strategy in two different cases.

\section{Task B}

Problem: The interest rate on investment into the business of mafia is 100 percent a year. I deposit 1 million. In how many years will I have 16 million on my bank account?

Solution (wrong): Let us suppose that there will be 16 million on the bank account in 3 years (the false assumption). This means I have 2 million after 1 year, 4 million after two years, and 8 million after 3 years. This is not enough; I need 16, which is twice as much. This means I have to double my initial guess. Answer: I will have the required sum in 6 years.

Clarification: If this result is tried and tested it proves to be incorrect. The problem is not based on a direct proportion but on an exponential function.

Task C

Problem: 591 pupils are enrolled in three clubs that take place at the same time. The basketball club is attended by three times more pupils than the gymnastics club. 114 more pupils go to the swimming club than to the basketball club. How many pupils are enrolled in the gymnastics club? 
Solution (wrong): Let us suppose that it is 40 pupils that go to the gymnastics club (the false assumption). Then 120 go to the basketball club and 234 to the swimming club. This makes it 394 pupils altogether, which is not enough. Thus I must multiply the initial guess by $\frac{591}{394}$.

Answer: 60 pupils go to the gymnastics club.

Clarification: If we look at the solution quickly, it may not seem as an inappropriately used strategy. However, if the result is tried and tested, it proves to be incorrect. The problem is not based on a direct proportion but on a linear function $=k x+q$, where $q$ in a nonzero number.

Problems of other than linear nature were not set to the pupils in our research study. For the needs of our experiment, we take the UFA method only as a convenient propaedeutic to word problem solving using linear equations, not as an alternative way of solving word problems.

\section{The risks of selection of the false assumption}

Another pitfall in the use of the UFA strategy is the choice of the false assumption. An unfortunate selection of the guess can become an obstacle for the solver in case they have to multiply their guess by a non-whole number. This phenomenon can be illustrated on the solution of the following problem.

Task D

Problem: The price of a book was reduced at first by $40 \%$, and one month later to one half of the new price. The book now costs $150 \mathrm{CZK}$. What was its original price?

Solution: Let us suppose the original price was $1000 \mathrm{CZK}$. If we reduce the price as described above, we get the following:

$$
\begin{gathered}
1000-400=600 \\
600 \div 2=300
\end{gathered}
$$

The price after the reduction is $300 \mathrm{CZK}$ in this case. To get the final price $150 \mathrm{CZK}$ we have to divide our original guess by two.

Answer: The book originally costs $500 \mathrm{CZK}$.

If the guess were for example $400 \mathrm{CZK}$, the calculation would be as follows:

$$
\begin{gathered}
400-160=240 \\
240 \div 2=120
\end{gathered}
$$

Number 120 is too little, the result should be 150 . So we must increase the original guess. How much? It must be directly proportional, that is:

$$
400 \times \frac{150}{120}=500
$$

The choice of the guess can have a major influence on success in the solution of the problem. Already the lessons conducted within the preparatory stage of the experiment showed that some pupils tended to fail if they had to multiply the guess by a non-whole number. The participating teachers stated unanimously that this was an obstacle to mastering the UFA method for about one half of the pupils. However, it did not take long before pupils got the feel for a good choice of the initial guess, which is illustrated in the authentic solution of problem 1 from the written test in figure 3.

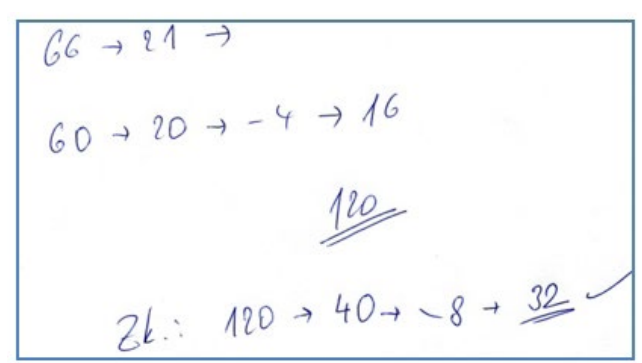

Figure 3: A pupil's solution illustrating a good choice of the initial guess. Problem: One third of an unknown whole number reduced by $20 \%$ is 32 . What is the unknown number? (source: pupil's solution) Note: Zk stands for Verification.

The solver, having conducted the first operation from the assignment, dropped their initial guess (66) and replaced it by a more opportune one (60).

Let us go back to one of the above-mentioned pitfalls of the use of the method UFA. The anticipated obstacle of inopportune choice of the false assumption that requires multiplication by a non-whole number and results in a pupil's failure to finish the solution could really be come across in the tests. However, the occurrence of the phenomenon was not very frequent: $1,0,3$, 2 (starting by problem 1). This phenomenon will not be further interpreted, as the main reason for including the UFA strategy into teaching was not to give the pupils an extra way of solving word problems but to enable them to construct equations with more ease in their future solution of word problems.

\section{Limitations of our research}

To conclude this section let us have a look at some limitations we are aware of. These limitations have to be taken into account when interpreting the results or when planning a new research study.

\section{Research sample}

We selected three pairs of classes according to the chosen teacher using the above listed criteria. Let us now discuss the limitations this selection bears:

With respect to the selected criteria, the teachers are regarded as comparable. However, there might be differences between them - both in the degree of their involvement and quality of teaching. We regard these differences as the first limitation of our study. "Comparability" of the involved teachers is based on the fact that we got to know them in the course of the one year work of posing and testing problems for the teaching experiment at the preparatory stage.

Another limitation is the "comparability" of the six classes. This "comparability" was assessed based on their school performance, which was stated according to school performance in mathematics at the end of the $7^{\text {th }}$ grade. Moreover, comparability of the experimental and control classes was assessed by a comprehensive test of knowledge and skills from the previous year, which was the same in all the six classes. The results were very similar in each pair of the classes.

With respect to the generalization of our hypothesis, we are 
limited by the size of our research sample of 147 pupils ( 72 pupils in the experimental and 75 pupils in the control groups). However, for statistical evaluation of our hypothesis, the size of the sample is sufficient with the $5 \%$ level of significance.

\section{Written test}

Selection of only one tool for evaluation of the research hypothesis may also be seen as a limitation. This tool was the written test. However, we are convinced that for the needs of verification of our research hypothesis this tool is sufficient.

\section{Used strategies}

All the problems in the written test can be solved in other ways than using linear equations. The Working Backwards strategy can be used successfully in problems 1, 3 and 4, the GuessCheck-Revise strategy in all the used problems. This might be a possible obstacle in the evaluation of the research hypothesis. However, if exclusively word problems that can only be solved using equations and cannot be solved in any other way had been used in the test, it would have been distortion of reality in the sense that word problems suitable for practicing the use of equations very often encourage spontaneous use of the Working Backwards and Guess-Check-Revise strategies (Eisenmann et al., 2017).

\section{CONCLUSIONS}

The here presented study describes one of the possible ways of facilitating solving of word problems to pupils. The study conducted with the research sample confirms the research hypothesis that the introduction of the UFA strategy before actually teaching the process of solving word problems can help pupils construct equations.

In accordance with the Phylogenesis and Ontogenesis Theory, we tried to show that it is worthwhile to reiterate the phylogenetic development of the concept of a variable with pupils in lessons.

It is generally agreed on that the greatest difficulty in the solution of word problems at schools is their mathematization. The process of the mathematization of a word (numerical) problem is based on the recognition of three types of information present in the problem wording. These are - usually numerical values or descriptions of variables, relations between data from the assignment, and questions. It is quite easy to discern the question in the problem wording. What is really difficult is to pinpoint the variables. Only after stating the variables and unknowns is it possible to study the relations among them.

The formation of the concept of a variable is important for the transition from arithmetic to algebra. It is crucially important that pupils should grow aware of the fact that the choice of the guess (the false assumption) has no impact. If pupils realize this they are more likely to grasp the concept of a variable that must be introduced to the solution of a problem if we want to construct an equation.

\section{Further research and open questions}

Further research should focus on several different areas. The first one is the relation of the reading comprehension ability and the UFA strategy and their impact on the success of constructing equations. The research question could be whether pupils with a lower level of reading comprehension skills will be equally successful when constructing equations having been introduced to the UFA strategy as pupils with a higher level of reading comprehension skills.

We did not work with pupils as individuals in this study. They were a part of the whole and the groups were perceived as relatively homogenous. Another area in which the research could be developed is the area of individual pupils with respect to their school performance in mathematics and mother tongue and their ability to construct equations, both in the experimental group (that is having been taught the UFA strategy) and in the control group.

The results of further research should be supported by more methods than only analysis of pupils' written tests. This analysis could be supplemented by structured interviews with teachers and a questionnaire survey with pupils.

\section{REFERENCES}

Artigue, M., Haspekian, M. and Corblin-Lenfant, A. (2014) 'Introduction to the theory of didactical situations (TDS)', In A. Bikner-Ahsbahs and S. Prediger (eds.), Networking of theories as a research practice in mathematics education: Authored by the networking theories group, Cham, Heidelberg, New York (NY), Dordrecht, London: Springer.

Bednarz, N. and Dufour-Janvier, B. (1994) 'The emergence and development of algebra in a problem solving context: A problem analysis', In J.P. da Ponte and J.F. Matos (eds.), Proceedings of the International Conference for the Psychology of Mathematics Education: Volume II, pp. 64-71, Lisbon: IG for PME.

Blažek, R. and Příhodová, S. (2016) Mezinárodni šetření PISA 2015: Národní zpráva [PISA 2015 results: Country overview], Prague: Czech School Inspectorate.

Boman, E.C. (2009) 'False position, double false position and
Cramer's rule', The College Mathematics Journal, Vol. 40, No. 4, pp. 279-283. https://doi.org/10.4169/193113409x458732

Boonen, A.J.H., van der Schoot, M., van Wesel, F., de Vries, M.H. and Jolles, J. (2013) 'What underlies successful word problem solving? A path analysis in sixth grade students', Contemporary Educational Psychology, Vol. 38, No. 3, pp. 271-279. https://doi. org/10.1016/j.cedpsych.2013.05.001

Boonen, A.J.H., de Koning, B.B., Jolles, J. and van der Schoot, M. (2016) 'Word problem solving in contemporary math education: A plea for reading comprehension skills training', Frontiers in Psychology, Vol. 7, Article 191, pp. 1-10. https://doi. org/10.3389\%2Ffpsyg. 2016.00191

Brousseau, G. (1997) Theory of didactical situations in mathematics, Dordrecht: Kluwer Academic Publisher.

Brown, T. and Heywood, D. (2010) 'Geometry, subjectivity and the seduction of language: the regulation of spatial perception', 
Educational Studies in Mathematics, Vol. 77, No. 2-3, pp. 351367. https://doi.org/10.1007/s10649-010-9281-2

Bruder, R. and Weiskirch, W. (2013) CAliMERO-computer-algebra im mathematikunterricht: Entdecken, rechnen, organisieren: Lineare algebra / analytische geometrie: Schülermaterialien, Münster: Schroedel Verlag.

Břehovský, J., Eisenmann, P., Ondrušová, J., Přibyl, J. and Novotná, J. (2013) 'Heuristic strategies in problem solving of 11-12-yearold pupils', In J. Novotná and H. Moraová (eds.), Proceedings of SEMT '13, pp. 75-82, Prague: Charles University in Prague.

Bunt, L.N.H., Jones, P.S. and Bedient, J.D. (1978) The historical roots of elementary mathematics, New York (NY): Dover Publications, Inc.

Bush, S.B. and Karp, K.S. (2013) 'Prerequisite algebra skills and associated misconceptions of middle grade students: A review', The Journal of Mathematical Behavior, Vol. 32, No. 3, pp. 613632. https://doi.org/10.1016/j.jmathb.2013.07.002

Cajori, F. (1890) The teaching and history of mathematics in the United States, Washington: Goverment Printing Office.

Chabert, J.-L. (ed.) (1999) A history of algorithms: From the pebble to the microchip, Berlin, Heidelberg: Springer-Verlag.

Chace, A.B., Bull, L. and Manning, H.P. (1929) The Rhind mathematical papyrus: British museum 10057 and 10058: Photographic facsimile, hieroglyphic transcription, transliteration, literal translation, free translation, mathematical commentary, and bibliography in two volumes, Oberlin: Mathematical Association of Mathematica.

De Corte, E., Greer, B. and Verschaffel, L. (2000) Making sense of word problems, Lisse: Swets \& Zeitlinger.

Descartes, R. (1954) The Geometry of René Descartes: With a Facsimile of the First Edition, translated from French and Latin by D.E. Smith and M.L. Latham, New York: Dover Publication, Inc.

Dubinsky, E., Weller, K., McDonald, M.A. and Brown, A. (2005) 'Some historical issues and paradoxes regarding the concept of infinity: An APOS-based analysis, Part 1', Educational Studies in Mathematics, Vol. 58, No. 3, pp. 335-359. https:// doi.org/10.1007/s10649-005-2531-z

Eisenmann, P., Novotná, J., Přibyl, J. and Břehovský, J. (2015) 'The development of a culture of problem solving with secondary students through heuristic strategies', Mathematics Education Research Journal, Vol. 27, No. 4, pp. 535-562. http://dx.doi. org/10.1007/s13394-015-0150-2

Eisenmann, P., Přibyl, J., Novotná, J., Břehovský, J. and Cihlář, J. (2017) 'Volba řešitelských strategií v závislosti na věku' [Choice of heuristic strategies with respect to age], Scientia in educatione, Vol. 8, No. 2, pp. 1-19.

Filloy, E. and Rojano, T. (1989) 'Solving equations: the transition from arithmetic to algebra', For the Learning of Mathematics, Vol. 9, No. 2, pp. 19-25.

Fischer, A. (2009) 'Zwischen bestimmten und unbestimmten Zahlen - Zahl- und Variablenauffassungen von Fünftklaesslern', Journal für Mathematik-Didaktik, Vol. 30, No. 1, pp. 3-29. https://doi.org/10.1007/bf03339071

Furinghetti, F. and Radford, L. (2002) 'Historical conceptual developments and the teaching of mathematics: from phylogenesis and ontogenesis theory to classroom practice', In L. English (ed.), Handbook of international research in mathematics education (pp. 631-654), New Jersey: Lawrence Erlbaum
Gick, M.L. (1986). 'Problem-solving strategies', Educational Psychologist, Vol. 21, No. 1-2, pp. 99-120. https://doi.org/10 $\underline{.1080 / 00461520.1986 .9653026}$

Goodson-Epsy, T. (1998) 'The role of reification and reflective abstraction in the development of abstract thought: Transitions from arithmetic to algebra', Educational Studies in Mathematics, Vol. 36, No. 3, pp. 219-245. https://doi. org/10.1023/a:1003473509628

Høyrup, J. (2002) Lenghts, widths, surfaces: A portrait of old Babylonian algebra and its kin, Berlin, New York (NY): Springer.

Jacobs, V.R., Franke, L.M., Carpenter, T.P., Levi, L., and Battey, D. (2007) 'Professional development focused on children's algebraic reasoning in elementary school', Journal for Research in Mathematics Education, Vol. 38, No. 3, pp. 258-288. https:// doi.org/10.2307/30034868

Jeřábek, J., Lisnerová, R., Smejkalová, A. and Tupý, J. (eds.) (2013) Rámcový vzdélávací program pro základní vzděláváni [The framework educational programme for basic (Primary and Lower Secondary) education], Prague: The Ministry of Education, Youth and Sports.

Jupri, A. and Drijvers, P.H.M. (2016) 'Student difficulties in mathematizing word problems in algebra', EURASIA Journal of Mathematics, Science \& Technology Education, Vol. 12, No. 10, pp. 2481-2502. https://doi.org/10.12973/eurasia.2016.1299a

Katz, V., Dorier, J.L., Bekken, O. and Sierpinska, A. (2000) 'The role of historical analysis in predicting and interpreting students' difficulties in mathematics', In J. Fauvel and J.V. Maanen (eds.), History in mathematics education (pp. 149-161), Dordrecht: Kluwer Academic Publisher.

Lewis, A.B. (1989) 'Training students to represent arithmetic word problems', Journal of Educational Psychology, Vol. 81, No. 4, pp. 521-531. https://doi.org/10.1037/0022-0663.81.4.521

Lewis, A.B. and Mayer, R.E. (1987) 'Students' miscomprehension of relational statements in arithmetic word problems', Journal of Educational Psychology, Vol. 79, No. 4, pp. 363-371. http:// doi.org/10.1037//0022-0663.79.4.363

Linchevski, L. and Herscovics, N. (1996) 'Crossing the cognitive gap between arithmetic and algebra: Operating on the unknown in the context of equations', Educational Studies in Mathematics, Vol. 30, No. 1, pp. 39-65. https://doi.org/10.1007/bf00163752

Lumpkin, B. (1996) 'From Egypt to Benjamin Banneker: Africans origins of false position solutions', In R. Calinger (ed.), Vita mathematica: Historical research and integration with teaching (pp. 279-303), Washington, DC: The mathematical association of America.

Morin, L.L., Silvana M.R.W., Hester, P. and Raver, S. (2017) 'The use of a bar model drawing to teach word problem solving to students with mathematics difficulties', Learning Disability Quarterly, Vol. 40, No. 2, pp. 91-104. https://doi. org/10.1177/0731948717690116

National Council of Teachers of Mathematics (2000) Principles and standards for school mathematics, Reston, VA: The National Council of Teachers of Mathematics.

Novotná, J. (2000a) Analýza řešení slovních úloh [Analysis of word problems solution], Prague: Charles University in Prague.

Novotná, J. (2000b) 'Students' levels of understanding of word problems', Regular lecture, ICME 9, Tokyo/Makuhari, Japan. In H. Fujita (ed.), ICME 9: Abstracts of plenary lectures and regular lectures, pp. 96-97, Tokyo/Makuhari, Japan. 
Novotná, J., Eisenmann, P. and Přibyl, J. (2014) 'Impact of heuristic strategies on pupils' attitudes to problem solving', In M. Houška, I. Krejčí and M. Flégl, (eds.), Proceedings of Efficiency and Responsibility in Education 2014, pp. 514-520, Prague: Czech University of Life Sciences.

Novotná, J., Eisenmann, P., Přibyl, J., Ondrušová, J. and Břehovský, J. (2014) 'Problem solving in school mathematics based on heuristic strategies', Journal on Efficiency and Responsibility in Education and Science, Vol. 7, No. 1, pp. 1-6. https://doi. org/10.7160/eriesj.2014.070101

Ofir, R. and Arcavi, A. (1992) 'Word problems and equations: An historical activity for the algebra classroom', The Mathematical Gazette, Vol. 76, No. 475, pp. 69-84. https://doi. org $/ 10.2307 / 3620379$

Palečková, J., Tomášek, V. and Blažek, R. (2014) Mezinárodní šetřeni PISA 2012: Národní zpráva [PISA 2012 results: Country overview], Prague: Czech School Inspectorate.

Pólya, G. (2004) How to solve it: A new aspect of mathematical method, Princeton: Princeton University Press.

Přibyl, J., Eisenmann, P. and Gunčaga, J. (2018) 'The phenomenon of false assumption in historical and educational texts', Science
\& Education, Vol. 27, No. 7-8, pp. 737-767. https://doi. org/10.1007/s11191-018-0005-9

Smith, D.E. (1929) A source book in mathematics: I \& II volume, New York, NY: McGraw Hill Book Company.

Stacey, K. and MacGregor, M. (2000) 'Learning the algebraic method of solving problems', Journal of Mathematical Behavior, Vol. 18, No. 2, pp. 149-167. https://doi.org/10.1016/ s0732-3123(99)00026-7

StatSoft, Inc. (2013). Statistica (data analysis software system), version 12. http://statistica.io

Verschaffel, L., De Corte, E. and Pauwels A. (1992) 'Solving compare problems: an eye movement test of Lewis and Mayer's consistency hypothesis', Journal of Educational Psychology, Vol. 84, No. 1, pp. 85-94. http://doi.org/10.1037/0022$\underline{0663.84 .1 .85}$

Winicki, G. (2000) 'The analysis of regula falsi as an instance for professional development of elementary school teachers', In V. Katz (ed.), Using history to teach mathematics: An international perspective (pp. 129-133), Washington, DC: Mathematical Association of America. 